University of Nebraska - Lincoln

DigitalCommons@University of Nebraska - Lincoln

$9-2013$

\title{
Using Buttons to Better Manage Online Presence: How One Academic Institution Harnessed the Power of Flair
}

Marcia L. Dority Baker

University of Nebraska-Lincoln, mdority_baker2@unl.edu

Follow this and additional works at: https://digitalcommons.unl.edu/lawlibrary

Dority Baker, Marcia L., "Using Buttons to Better Manage Online Presence: How One Academic Institution Harnessed the Power of Flair" (2013). The Marvin and Virginia Schmid Law Library. 11.

https://digitalcommons.unl.edu/lawlibrary/11

This Article is brought to you for free and open access by the Law, College of at DigitalCommons@University of Nebraska - Lincoln. It has been accepted for inclusion in The Marvin and Virginia Schmid Law Library by an authorized administrator of DigitalCommons@University of Nebraska - Lincoln. 


\title{
Using Buttons to Better Manage Online Presence: How One Academic Institution Harnessed the Power of Flair
}

\author{
Marcia L. Dority Baker \\ Schmid Law Library, University of Nebraska College of Law, \\ P.O. Box 830902, Lincoln, NE 68583-0902; email mdoritybaker@unl.edu
}

\begin{abstract}
This article provides a case study of how the University of Nebraska College of Law and Schmid Law Library use "buttons" to manage Law College faculty members' and librarians' online presence. Since Google is the primary search engine used to find information, it is important that librarians and libraries assist Web site visitors in finding relevant information about faculty members at an academic institution. Easily identifiable buttons allow visitors to navigate to faculty scholarship in the University of Nebraska- Lincoln Digital Commons, SSRN Web site, or both, in an academic service such as lessons from the Center for Computer-Assisted Legal Instruction and in social software sites like Twitter, Facebook, or LinkedIn. The case study includes (1) how the project was implemented, (2) the feedback and results of a survey, and (3) an analysis of Web site statistics, clicks, and links data gathered via Google Analytics. This project was a partnership between the Law College Communications Department, Law College Administration, and the Law Library, involving law faculty, staff, and librarians. The buttons project was considered a successful venture by participating faculty members; it also provided an opportunity for face-to-face conversation between faculty members and librarians about digital scholarship and social media in the academic environment.
\end{abstract}

Keywords: online search, finding information, buttons, managing online presence, Digital Commons, SSRN, faculty Web pages, Google Analytics, Twitter 


\section{Introduction}

How do you find someone online? For many people, Google is the first stop when searching for a person, place, or thing; according to a recent Pew report, 83 percent of Americans prefer it to other search engines to find information (Purcell, Brenner, and Rainie 2012). It has become so normal to start with Google that "to google" is now used as a verb. Since this is the new norm of information searching, how do librarians and libraries better assist users in finding information, especially the people and relevant resources attached to the libraries or colleges?

Searching outside the box for information is an older concept than most people assume. Technology has allowed conversation between individuals or multiple users to flourish in a number of ways: Mobile smartphones, computers, social media sites, and robust search engines complement face-to-face interaction. In reviewing social networking literature, an article from Computer (Weaver and Morrison 2008, 97) nicely summarized that "social networking has come to mean individuals using the Internet and Web applications to communicate in previously impossible ways." Since people are using evolving technology to communicate and to find information, it makes sense that libraries and academic institutions are finding new ways to use technology to help users locate relevant information in a timely manner.

The University of Nebraska College of Law and Schmid Law Library recently sought ways to improve the content and timeliness of faculty Web pages. Affectionately called the "button project," it involved an effort to provide easily identifiable buttons on faculty Web pages linking visitors to faculty scholarship with a single click of the button. It began in May 2011 after a conversation at a faculty retreat on how to better promote the Law College and faculty scholarship to a larger audience. The University of Nebraska College of Law has a good Web site; its homepage was ranked 8th in the Top 10 Law School Homepages of 2011 study (Skalbeck 2012). Despite this high ranking, however, faculty pages tended to be static in nature, usually updated before the academic year began or when new faculty members were hired. Adding buttons would serve two purposes: (1) direct users to current scholarship and lessons created by University of Nebraska College of Law faculty and librarians and (2) promote the Law College and Schmid Law Library's social media presence.

After several brainstorming sessions with the associate dean of faculty, two law librarians, and the Law College communications director, the decision was made to start with the following buttons: UNL (University of Nebraska-Lincoln) Digital Commons (http://digitalcommons.unl.edu), SSRN (Social Science Research Network) (http://www.ssrn.com), and LinkedIn. Faculty members or law librarians who wanted to support the University of Nebraska College of Law or Schmid Law Library's social media presence could also have buttons for each institution's Facebook and Twitter pages (see Figure 1). A clear directive was given to everyone in- 


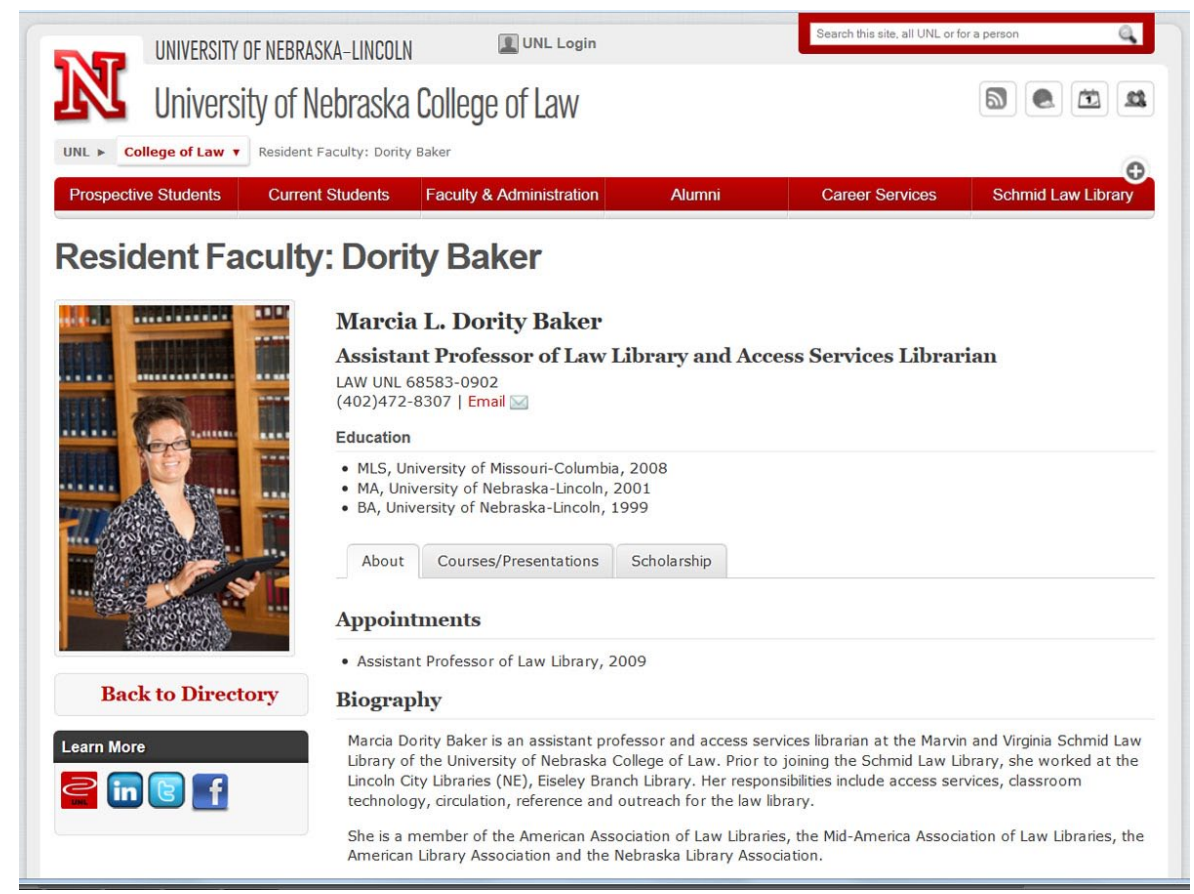

Figure 1. Library faculty page with buttons.

volved with the project: We would not link to individual Facebook profiles but would link to a professor's Twitter feed if he or she desired. As more faculty use Twitter, this option has become a standard button on faculty pages; in addition to the dean, there are approximately fourteen faculty members and librarians using Twitter. Several other Law College departments are using Twitter to communicate with students, alumni, and other interested users; these include the Schmid Law Library, the Law College Admissions Department, and the Space, Cyber and Telecommunications Law Master of Laws (LLM) program.

Two recent button additions on faculty Web pages are (1) CALI (Center for Computer-Assisted Legal Instruction) linking to lessons created by faculty and law librarians (see Figure 2) and (2) promotional buttons linking to faculty-supported organizations such as the mentorship program WILE (Women in Legal Education). As other professional opportunities become available, we anticipate creating but-

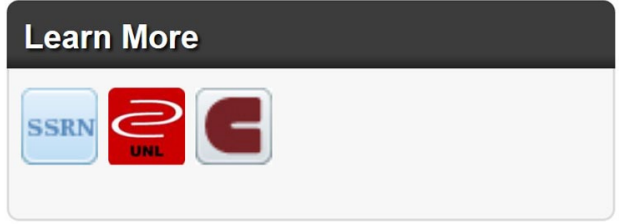

Figure 2. Faculty page buttons for SSRN, UNL Digital Commons and CALI. 


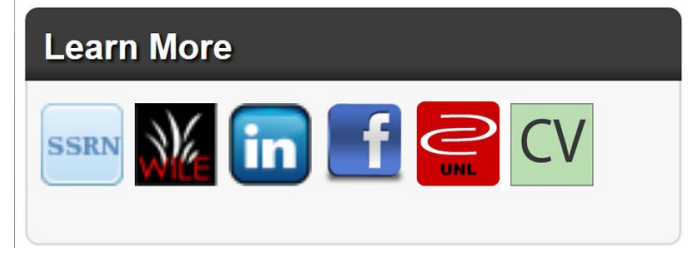

Figure 3. Faculty page buttons for SSRN, WILE, LinkedIn, Facebook, UNL Digital Commons and Curriculum Vitae.

tons or using recognized buttons to link our faculty and librarians with those options. The recently added "CV" button is a good example of creating a button to fit a specific request: Several faculty members wanted a link to their curriculum vitae (CV) from their Law College faculty Web page (see Figure 3). While LinkedIn has become the professional networking and online resume option for many people, it does not include profile sections for service and committee work that many professors and librarians participate in. Including the CV button on a faculty member's Web page provides access to their current $\mathrm{CV}$ for interested visitors or those not using LinkedIn.

Once decision-making meetings were done and buttons created, it was time to roll out the buttons project. First, we added buttons to faculty Web pages of a small test group: the associate dean for faculty, a faculty member, and myself, to demonstrate how the different buttons would display on individual Web pages (see Figure 1). Then, each of the law librarians contacted an assigned group of Law College faculty members during the 2011-12 academic year to discuss adding buttons to individual faculty pages. During the small group or individual meetings, the law librarians had the opportunity to educate professors as to why they should add their scholarship to the UNL Digital Commons institutional repository and SSRN. There was also time to discuss social media sites, such as Facebook and Twitter, and to answer questions on creating a LinkedIn profile. Finally, as Law College faculty members said "yes" to displaying buttons on their Web pages, staff working with the project added appropriate buttons linking to faculty material in the UNL Digital Commons and/or SSRN and social media sites such as Twitter.

Initially, a Law College staff member and I added buttons to each faculty members' and law librarians' Web pages as they agreed to participate in the project. We did not ask Law College IT staff to add buttons to faculty Web pages because their time is better spent on other Law College technology needs. To be nimble, the button project required that a few law school staff make easy additions to Web pages as requested and pre-determined. I quickly added buttons to law librarians' Web pages to show how the end product would look for faculty members wanting to see buttons before committing. As law librarians met with professors to discuss button 
options, we added requested button(s) in a timely manner, providing fresh content on faculty pages. In a few instances, we had to wait on material to be added in the UNL Digital Commons or for faculty members to upload material to SSRN before adding the button with link to the professor's page; this way buttons were usable to site visitors and clickable for more information (King 2008).

The process of finding or creating each button and adding appropriate buttons to a faculty member's Web page was fairly simple. Some buttons, such as LinkedIn, Facebook, and Twitter buttons, were taken from each of the social media Web sites' collections of buttons for members to use. A Law College staff member created other buttons used on the faculty Web pages. The SSRN button was made after an e-mail conversation about linking Web site visitors from a faculty member's Web page to their SSRN author's page; we wanted to verify that the SSRN logo was used appropriately. A similar process was followed to create CALI and UNL Digital Commons buttons; care was taken to attribute proper use of the CALI logo for the button after an e-mail conversation with the CALI director of curriculum development. The UNL Digital Commons button was a new creation because the UNL institutional repository did not have a logo; we used bepress's Digital Commons logo on a Nebraska-red template button with permission from UNL Digital Commons. The CV and WILE buttons were created in-house; the CV button is a quick link to a PDF of a professor's CV, while the WILE button a visual way to promote the Association of American Law Schools (AALS) chapter mentoring program for women in legal education.

Buttons were organized by the type of content the button linked visitors to, in order of importance: faculty publications links, professional online presence for teaching or research links, then social media links. If a faculty member wanted to include all available buttons on his or her Web page, the appropriate order from left to right was UNL Digital Commons, SSRN, LinkedIn, CALI, WILE, Twitter, Facebook, and CV. Web page design research (Krug 2006) shows users begin at the left side of a Web site and read across the page.

\section{Promotion of a Cause}

A quick Google search of the Law College faculty and librarians consistently finds each faculty member's Web page at the top of the results list. Web pages now function as a landing page for visitors interested in finding more information about a particular faculty member at the University of Nebraska College of Law. By harnessing the power of this central hub, we provide a better user experience for our visitors. The addition of recognizable buttons to faculty pages gives visitors the opportunity to navigate through many different areas in which faculty or librarians are working. Instead of users wading through a number of Google results for 
contact information, publications, classes taught, or service, faculty pages become a one-stop shop of relevant content. For example, by linking from a faculty page to the UNL Digital Commons, visitors can locate a faculty member's scholarship housed within the digital collection. The UNL Digital Commons is actively adding all available faculty scholarship to the University of Nebraska-Lincoln digital repository, allowing users to eventually access an entire career of work. While most academic scholarship can be located in a subject-specific database, often behind a paywall, the UNL Digital Commons collection houses articles, working papers, and other research collections searchable by college, special collection, or subject area, adding to the wealth of knowledge created by the UNL academic community. The primary goal of the UNL Digital Commons is to provide, house, and preserve the University of Nebraska's research in one open access repository for free, to all interested users.

Not only does the eye-friendly location of buttons connect visitors to faculty research and scholarship, it also provides a broader picture of faculty and librarian involvement in their professions. A number of law faculty members and librarians are using Twitter for professional commentary in their subject area. The addition of a Twitter button makes it easier for people to find and follow a particular faculty member on Twitter, especially if the faculty member's Twitter handle is different than his or her user name (e.g., "@ADR_Prof" is our Mediation and Arbitration professor's handle). The WILE mentorship program is another service opportunity faculty members are involved in and want to promote; this button links users to the WILE program page and contact information. An additional button useful for students is the CALI button, linking to CALI lessons created by faculty and librarians at the University of Nebraska College of Law. Promoting CALI on an individual faculty member's Web page quickly demonstrates to students and colleagues which professors have created CALI tutorials in their teaching area.

\section{Faculty Survey}

I used a simple four-question Survey Monkey survey to solicit feedback from the Law College faculty asking (1) why they agreed to have buttons on their faculty Web page, (2) if they received feedback regarding use of buttons, (3) if they were already using the UNL Digital Commons repository and/or SSRN Web site, and (4) if they thought adding buttons to faculty Web pages was a good idea (see Figure 4).

The survey was purposely kept brief because members of the Law College faculty were busy with the end of fall 2012 semester activities. I decided on Survey Monkey for several reasons: I am familiar with and have used it for a number of other surveys, I find it easy to create and share, and it allows for anonymous results and/or comments to survey questions. One challenge in writing any survey 
I.Why did you decide to have buttons (UNL Digital Commons, SSRN, Twitter, Facebook, Linkedln, CALI,WILE) displayed on your faculty page? (I 3 free-text responses).

2. Have you received comments from people who found your scholarship via the UNL Digital Commons and/or SSRN buttons on your faculty webpage? If so, would you share in the comment box? $(n=12 ; " N o "=12$; skipped question = I).

3. Did you have scholarship or publications in the UNL Digital Commons and/or SSRN prior to the law librarians asking you to participate? $(n=13$; "Yes, UNL Digital Commons" = I; "Yes, SSRN" = 4; "Yes, both UNL Digital Commons \& SSRN" = 4; "No" $=4$; skipped question $=0$ ).

4. Do you think adding buttons to faculty pages was a good idea? $(n=1 \mathrm{I}$; Yes $=2$; skipped question $=2$ ).

Figure 4. Faculty Web page buttons survey and results.

question is determining how to ask a question for valid results. While "Yes" and "No" questions are simple to create, the data can be skewed by a poorly worded question; after several conversations with helpful law library faculty, the survey evolved from a three-question to a better-worded four-question product.

In late November 2012, I e-mailed the "LawFac" (Law Faculty at the University of Nebraska College of Law) listserv a short summary of this project, explained why I wanted their feedback, and provided a link to the buttons survey. The "LawFac" e-mail listserv includes 58 people: Law College faculty (37), Law College Administration (9), Law Library Faculty (6), Law- Psychology Faculty (4), Visiting Faculty (1), and Emeritus Faculty (1). There are currently 21 law professors with buttons on their Web pages, while several other faculty members have content in the UNL Digital Commons and/or SSRN but do not have buttons on their Web page. As of November 30, 2012, the survey generated 13 responses.

A mix of "Yes" and "No" questions with an optional comment box produced informative results. The most common response to Question 1 ("Why did you decide to have buttons [UNL Digital Commons, SSRN, Twitter, Facebook, LinkedIn, CALI, WILE] displayed on your faculty page?") was the desire to improve accessibility of faculty scholarship to colleagues and students. One particular comment reflected a common reason why faculty members said "Yes" to adding buttons to their faculty Web page: "so that faculty members at other schools, the media, and my students could track my scholarship." Other responses to why included the following: "connect users to articles easier," "show service work," and "to add visual content" to his or her faculty page. Two responses to Question 1 specifically mentioned that the faculty member participated because the law librarians asked him or her to be involved, 
which was a nice surprise. This may demonstrate that faculty want to better promote their work and the University of Nebraska College of Law, but do not have the time or resources to do so, and librarians can help bridge the gap between access to online scholarship and faculty online presence by suggesting how to better manage their digital academic content. Either way, the responses show communicating face-to-face with faculty members has a positive effect on a project of this nature.

The response to Question 2 ("Have you received comments from people who found your scholarship via the UNL Digital Commons and/or SSRN buttons on your faculty Web page? If so, would you share in the comment box?") was a resounding "No." Unfortunately, there has been no visitor feedback or comments directed to faculty in regards to the buttons on their pages. One possible reason could be that buttons are fairly common on Web pages, so many people may not realize the button is a new feature. Or, as Web pages are updated and content management systems (CMS) change, it is common to see Web site redesigns with new graphics, layout, and linking options.

Faculty members do receive feedback directly from the UNL Digital Commons and SSRN on publication downloads. The UNL Digital Commons author's dashboard, available from bepress, provides useful statistics for the discovery of material within the repository and tracks visitors to the author's collection. These data include download statistics, search query results, the institution that visitors originate from, referral Web sites, and more. Unfortunately, accurate information about which page a visitor linked from to access a faculty member's article is not clear. The UNL Digital Commons button on a faculty Web page links to the individual author's page or landing page in Digital Commons. This author's page then directs visitors to the appropriate publication for review of the abstract or to download; so the first statistic of where a visitor is coming from outside the digital commons repository is not collected, only the last page directing the user to a specific article. SSRN statistics are similar, providing the author with downloads for his or her article(s), citations, and rank.

Before the buttons project began, a handful of University of Nebraska College of Law faculty had scholarship in the UNL Digital Commons, had uploaded articles to SSRN, or both. The idea behind Question 3 ("Did you have scholarship or publications in the UNL Digital Commons and/or SSRN prior to the law librarians asking you to participate?") was to find out how many faculty members were participating before the initiative began. Since the start of this project, buttons have been added to a number of faculty pages as professors agreed to participate. Faculty members give permission for scholarship to be added to the institutional depository by e-mailing their publications list to their assigned librarian, who forwards the list to the UNL Digital Commons director. The UNL Digital Commons staff is responsible for gathering, organizing, and uploading faculty scholarship, including addressing copyright and format issues. SSRN operates in a similar fashion 
but makes faculty members responsible for uploading their articles and addressing both copyright and format requirements.

All of the eleven responses to Question 4 ("Do you think adding buttons to faculty pages was a good idea?") were positive: "LawFac" listserv members who answered this question think adding buttons to faculty pages was a good idea. This feedback demonstrates that the project was worth the time and effort involved in meeting with faculty members to discuss their scholarship and how to best manage their online presence. As new professors join the Law College faculty, the law librarians discuss the UNL Digital Commons and SSRN during the library orientation. This promotes the buttons project and encourages new faculty members to share their scholarship on these platforms, which is especially useful for faculty transitioning from legal practice in law firms to academia. Professional scholarship is also an important component of academic tenure requirements. The law library can better support faculty scholarship and publishing success by reviewing how and where digital scholarship can be collected, viewed, and downloaded by the academic community. The buttons project is one such way academic librarians can assist faculty in managing their digital publications and online presence.

\section{Discussion and Conclusion}

The buttons experience has been beneficial for me as librarian; it is a unique opportunity to work with other organizations at the university, a new way to promote faculty scholarship and professional online presence, and has improved communication between Law College departments. Although increased discussion of faculty publications and response from the faculty survey are good feedback, I hoped to acquire better statistics from Google Analytics to show how useful buttons would be as an addition to faculty member's Web pages. Unfortunately, using Google Analytics to review faculty Web page statistics was more challenging than I expected, because the statistics I was hoping to find were not available: We were not tracking the number of clicks on external links. While buttons on faculty pages look great and link directly to individual faculty member's scholarship in SSRN and the UNL Digital Commons, there is almost no data to confirm how frequently the buttons are clicked. There is one button tracked by Google Analytics: the WILE button on two faculty member's Web pages. This button links to another law.unl.edu page, so statistics are available for the WILE button, which was clicked on at least once during this five-month time frame.

Although I did not get the information I hoped for, I did find a number of other interesting details about faculty Web pages in the Google Analytics statistics. For instance, during the time period of August 1-November 30, 2012, general traffic to the University of Nebraska College of Law homepage stemmed mostly from or- 
ganic (non-paid) Google searches, followed by referrals from other UNL Web pages. The same pattern was true for individual faculty pages during this same time; the primary referral traffic to faculty Web pages is from Google then unspecified UNL sites. Additional traffic sites include other search engines, law-related Web sites (tax or whistle-blowing), and social software sites such as Twitter, Wikipedia, and Facebook.

During this same time period, Google Analytics recorded clicks on the tabs on nineteen of 35 faculty Web pages, and one out of six law librarian Web pages. These faculty Web page tabs included About, Courses, Publications or Scholarship, Lectures, Research, and Noteworthy. Law College faculty members are responsible for the content within these tabs, which includes his or her biography and education information, current scholarship and/or research details, as well as professional awards or other noteworthy details. It might be assumed if visitors are clicking on established tabs on a faculty member's Web page, then visitors may be clicking on buttons linking to the UNL Digital Commons, SSRN Web site, or social software sites.

While it was disappointing not to have Google Analytics statistics, the feedback from faculty members demonstrates how useful the project was. Since the buttons project stemmed from conversation to better promote faculty scholarship and the University of Nebraska College of Law, I would suggest it has been a success. This project promoted discussion between the law librarians, law faculty, and the administration in regard to professional scholarship, social media, and privacy. The project also created a new way for several departments within the Law College to work collaboratively.

As the first stage of the button project comes to a close, we are now two years from the initial discussion at a faculty retreat. We will continue promoting the addition of buttons on faculty Web pages as new professors join the Law College and adding buttons to current faculty Web pages as appropriate. During the semester, I periodically search faculty publications in SSRN to check that the links are working and to see if remaining Law College faculty members without buttons have uploaded their first article. As a UNL Digital Commons administrator, I receive e-mails when new publications are uploaded to the repository, and I check those publications against the current button list on a faculty member's Web page. I have found that faculty ask more questions about scholarship in SSRN or the UNL Digital Commons depending on their publication opportunities or as professors join social media sites such as Twitter. Including buttons on faculty Web pages will be reviewed in 2013-14.

Hindsight is $20 / 20$, so I have a few suggestions for librarians interested in this project. First, explore what repository resources are available at your institution for faculty publications and scholarship (see the SPARC 2013 Digital Depositories Resources for further reading). Determine how this department is organized and who is responsible for collecting and uploading material and maintaining the tech- 
nology. The strong selling point for UNL Digital Commons is that the department does all work for faculty members who want to include scholarship in the repository. Second, does the library or librarian have support of administration to pursue such a project? The "buttons project" came about because Law College faculty, administration, and librarians wanted a new way to better promote faculty scholarship on a budget with current university resources: the UNL Digital Commons, the Law College's Web page, the Law College's use of SSRN, and staff creativity in creating buttons. Third, can the IT staff or library staff assist in adding buttons or badges to faculty Web pages? Sometimes Web site modifications or permissions have several departments through which to migrate, slowing down a project of this type. Finally, does the library have staff and calendar time available to complete the project? After two years of working on the button project, I still find faculty members without the appropriate buttons or have professors who now have time to discuss adding their publications to SSRN or the UNL Digital Commons. Once the initial promotion of the project is done during the first academic year, it must be maintained as new faculty are hired or schedules and priorities change.

Online presence, such as digital scholarship and faculty Web pages, is necessary in today's academic world, yet it was the opportunity for face-to- face conversation that made the button project effective. Being able to find the University of Nebraska College of Law faculty at the top of the Google search engine results and linking to faculty scholarship and service via the buttons provides a better user experience for visitors. Managing online presence is more than linking to relevant information; it is about building professional relationships within an academic environment to better promote our educational mission and service to our users.

\section{References}

King, David Lee. 2008. Designing the Digital Experience: How to Use Experience Design Tools and Techniques to Build Websites Customers Love. Medford, NJ: CyberAge Books/Information Today.

Krug, Steve. 2006. Don't Make Me Think! A Common Sense Approach to Web Usability, 2nd ed. Berkley: New Riders Pub.

Purcell, Kristen, Joanna Brenner, and Lee Rainie. 2012. “Pew Report: Search Engine Use 2012.” http://pewinternet.org/Reports/2012/Search-Engine-Use-2012.aspx

The Scholarly Publishing \& Academic Resources Coalition (SPARC). 2013. "Repository Resources." http://sparc.arl.org/theme/repositories

Skalbeck, Roger. 2012. “Top 10 Law School Home Pages of 2011.” http://papers.ssrn.com/sol3/ papers.cfm?abstract id=2001967

Weaver, Alfred C., and Benjamin B. Morrison. 2008. "Social Networking." Computer 41 (2):97-100. 